\title{
Malaria health seeking practices for children, and intermittent preventive treatment in pregnancy in Wakiso District, Uganda
}

\author{
David Musoke ${ }^{1}$, Rawlance Ndejjo ${ }^{1}$, Solomon Tsebeni Wafula ${ }^{1}$, Simon Kasasa ${ }^{2}$, \\ Jessica Nakiyingi-Miiro ${ }^{3}$, Miph Boses Musoke ${ }^{4}$
}

1. Department of Disease Control and Environmental Health, School of Public Health, College of Health Sciences, Makerere University, Kampala, Uganda.

2. Department of Epidemiology and Biostatistics, School of Public Health, College of Health Sciences, Makerere University, Kampala, Uganda.

3. London School of Hygiene and Tropical Medicine, London, United Kingdom.

4. School of Sciences, Nkumba University, Entebbe, Uganda.

\section{Email addresses of authors}

DM: dmusoke@musph.ac.ug; RN: rndejjo@musph.ac.ug; STW: swafula@musph.ac.ug; SK: skasasa@musph. ac.ug; JNM: jessica.nakiyingi-miiro@1shtm.ac.uk; MBM: musokemb@yahoo.com

\begin{abstract}
Background: Timely health care among children with suspected malaria, and intermittent preventive treatment (IPTp) in pregnancy avert related morbidity and mortality in endemic regions especially in sub-Saharan Africa. Malaria burden has steadily been declining in endemic countries due to progress made in scaling up of such important interventions.

Objectives: The study assessed malaria health seeking practices for children under five years of age, and IPTp in Wakiso district, Uganda.

Methods: A structured questionnaire was used to collect data from 727 households. Chi-square and Fisher's exact tests were performed in STATA to ascertain factors associated with the place where treatment for children with suspected malaria was first sought (government versus private facility) and uptake of IPTp.

Results: Among caretakers of children with suspected malaria, 69.8\% sought care on the day of onset of symptoms. The place where treatment was first sought for the children (government versus private) was associated with participants' (household head or other adult) age $(p<0.001)$, education level $(p<0.001)$ and household income $(p=0.011)$. Among women who had a child in the five years preceding the study, $179(63.0 \%)$ had obtained two or more IPTp doses during their last pregnancy. Uptake of two or more IPTp doses was associated with the women's education level $(p=0.006)$, having heard messages about malaria through mass media $(p=0.008)$, knowing the recommended number of IPTp doses $(p<0.001)$, and knowing the drug used in IPTp $(\mathrm{p}<0.001)$.

Conclusion: There is need to improve malaria health seeking practices among children and pregnant women particularly IPTp through programmes aimed at increasing awareness among the population.

Keywords: Health seeking behaviour, intermittent preventive treatment, malaria, children, pregnancy, Uganda.

DOI: https:/ / dx.doi.org/10.4314/ahs.v21 i4.28

Cite as: Musoke D, Ndejjo R, Wafula ST, Kasasa S, Nakiyingi-Mïro J, Musoke MB. Malaria health seeking practices for children, and intermittent preventive treatment in pregnancy in Wakiso District, Uganda. . Afri Health Sci. 2021;21(4):1722-32. https://dx.doi. org/10.4314/ahs.v21i4.28
\end{abstract}

\section{Corresponding author: \\ David Musoke, \\ Department of Disease Control and \\ Environmental Health, School of Public Health, \\ College of Health Sciences, Makerere \\ University, Kampala, Uganda. \\ Tel: +256414543872; \\ Email:dmusoke@musph.ac.ug}

\section{Introduction}

Malaria remains a major cause of morbidity and mortality in endemic countries particularly in sub-Saharan Africa including Uganda. Children under five years of age and pregnant women are high risk groups regarding malaria infection due to their low immunity. For that reason, global malaria prevention efforts such as access to long-lasting insecticidal nets (LLINs) and Indoor Residual Spraying (IRS) have put much emphasis on these groups to reduce the occurrence of malaria among
Health Sciences

C 2021 Musoke D et al. Licensee African Health Sciences. This is an Open Access article distributed under the terms of the Creative commons Attribution License (https://creativecommons.org/licenses/BY/4.0), which permits unrestricted use, distribution, and reproduction in any medium, provided the original work is properly cited. 
them ${ }^{1}$. There were 272,000 deaths due to malaria among children under five years in 2018, which accounted for $67 \%$ of total deaths worldwide ${ }^{1}$. In addition, approximately 125 million pregnant women globally are at risk of acquiring malaria infections annually, and 24\% of these occur in sub-Saharan Africa ${ }^{2}$. Pregnant women affected by malaria infections can experience devastating effects including severe anemia, increased risk of preterm delivery, low birth weight, intrauterine death, stillbirth, miscarriages and maternal deaths ${ }^{3,4}$. The World Health Organization (WHO) recommends intermittent preventive treatment of malaria in pregnancy (IPTp) as part of the three-pronged strategic approach to malaria prevention and control for regions with high malaria endemicity and transmission including sub-Saharan Africa. The WHO policy also includes the use of LLINs, and effective management of clinical malaria and anemia including among children and pregnant women ${ }^{5}$. According to the policy, all pregnant women should receive IPTp during their antenatal care (ANC) visits which should commence early in the second trimester. Each IPTp dose with sulphadoxine-pyrimethamine (IPTp-SP) should be given at least a minimum 1 month apart but ensuring that at least 3 doses are given during pregnancy6. Due to potential mosquito resistance to insecticides used in IRS, and other challenges in malaria prevention in endemic countries including Uganda, IPTp is a key control strategy against malaria ${ }^{1}$. The WHO has also recommended integrated community case management (iCCM) of childhood illnesses including malaria1 which is carried out by Community Health Workers (CHWs) locally referred to as village health teams (VHTs) in Uganda.

Although iCCM and IPTp policies have been implemented in many sub-Saharan African countries including Uganda for many years, there is still low uptake ${ }^{1,7,8}$. The factors responsible for the low uptake of IPT include number and timing of ANC visits, low awareness, low education level ${ }^{9,10}$ and high costs ${ }^{11}$. Some systemic factors such as inadequate drug supply, poor skills and attitudes of health providers, shortage of health workers, and skewed access to ANC have also been cited ${ }^{12}$. On the other hand, iCCM has faced many challenges in Uganda and other malaria endemic countries mainly around financing which has not only affected training of CHWs but also availability of medicines and other supplies such as rapid diagnostic tests (RDTs) ${ }^{1}$. Factors such as deficiencies in the health system, long distance to nearest health care facilities (HCFs), and high cost of treatment services are also known to impede the uptake of most health services in Uganda including IPT ${ }^{13}$. The success of treatment of children including under iCCM, and IPTp in malaria endemic countries is therefore dependent on various health systems building blocks including governance, financing, human resources, access to essential medicines, information systems and service delivery ${ }^{14}$.

Malaria is still endemic in most parts of Uganda where it is responsible for about $65 \%$ of maternal mortality, and $60 \%$ of spontaneous abortions among pregnant wom$\mathrm{en}^{15}$, as well as a prevalence of $19 \%$ among children under five years of age ${ }^{16}$. Although Uganda is implementing the IPTp policy, its uptake is still low. According to the 2016 Uganda Demographic and Health Survey (UDHS), only $16.8 \%$ of pregnant women had received three or more doses of IPTp-SP, $45.0 \%$ had received two or more doses, and $76.9 \%$ had received at least one $\operatorname{dose}^{17}$. Several challenges affect the uptake of malaria control interventions including IPTp, and prompt diagnosis and treatment among children and pregnant women in Uganda. These challenges include inadequate health care financing, limited coverage of HCFs, and irregular supply and underutilisation of drugs ${ }^{18}$. There is also low retention of staff at HCFs, as well as ineffective supervision, coordination and leadership ${ }^{18}$. Seeking IPTp is essential in mitigating adverse effects associated with maternal malaria, and also reduces demographic and socioeconomic disparities ${ }^{19}$. Although studies have been conducted in primary health care settings in Ugan$\mathrm{da}$, there is need to further understand malaria health seeking behaviours in communities including among children and pregnant women. This study therefore assessed the malaria health seeking practices including for children under five years of age and pregnant women in Wakiso district, Uganda.

\section{Methods \\ Study design and data collection}

The study was cross-sectional and collected quantitative data. The data was collected using a structured questionnaire focusing on: socio-demographic characteristics; malaria health seeking practices for children (when a child was taken to seek healthcare when suspected of being ill, where healthcare was sought for the children, distance travelled to seek healthcare, and whether treatment was paid for); general household health seeking practices (nearest HCF to the home, the distance of the nearest HCF to the home, mode of transport to the nearest HCFs, whether the nearest HCF was used when a household member was suspected of having malaria 
and reasons for non-use, knowledge of the existence of CHWs in the village and whether they had malaria medicine, and missing of school by children due to malaria); and knowledge and practices on IPTp (knowledge of drug used for IPTp, taking drugs for IPTp for the last pregnancy and reason for not doing so, and number of times they took drugs for IPTp during the last pregnancy). The household questionnaire was administered once for each household involved in the study. The study participants were household heads or other responsible adults such as spouses that were found at home during data collection. However, questions concerning uptake of IPT were asked to only female participants. For this reason, the questionnaire used in the study had a section that was specific for only females.

\section{Study area and sampling}

The study was carried out in Ssisa sub-county, Wakiso district, Uganda located in the central region of the country. Wakiso district has 7 health sub-districts with a total of $229 \mathrm{HCF}$ where $73 \%$ are private and serve over $70 \%$ of the population. Ssisa sub-county is made up of 11 rural and peri-urban parishes of Bulwanyi, Bweya, Kitende, Nakawuka, Namulanda, Nankonge, Ngongolo, Nkungulutale, Nsaggu, Ssisa and Wamala which were all involved in the study. The population in the sub-county is engaged in various economic and social activities such as agriculture, animal husbandry, petty trading, stone quarrying, brick making and sand mining. Ssisa sub-county has a population of 94,238 and average household size of 3.820 . A total of 727 randomly selected households from 29 villages were involved in the study as described in our earlier publication ${ }^{21}$. The number of villages from each parish involved in the study was determined proportionate to the number of households per parish (data obtained from Uganda Bureau of Statistics) which ranged from 1 (Bulwanyi, Nankonge, Ngongolo, Nsaggu, Ssisa and Wamala) to 7 villages (Kitende and Namulanda). Households involved in the study were randomly selected.

\section{Data management and analysis}

Data were entered in SPSS version 10 (Chicago, Illinois, USA) and analysed in STATA version 13.0 (Stata Corp, Texas, USA). Univariate and bivariate statistical tests were employed. Dependent variables of the study were: the place where treatment was sought by households that had a child below five years who was suspected of having malaria in the two weeks preceding the study (either private or government $\mathrm{HCFs}$ ); and uptake of two or more IPTp doses during their last pregnancy among women who had a child within the preceding five years. Chi-square and Fisher's exact tests were performed to ascertain the independent variables that were associated with the dependent variables. The independent variables included individual (such as gender, age, education, occupation, religion, and knowledge of the cause of malaria) and household characteristics (such as average household income, distance to the nearest facility, and the number of household members).

\section{Ethical considerations}

Ethical approval to conduct the study was obtained from Makerere University School of Public Health Higher Degrees, Research and Ethics Committee (11353). The research was also approved and registered at the Uganda National Council for Science and Technology (SS 3294). Participation in the study was voluntary, and participants provided written informed consent after explaining to them the purpose of the research including the anticipated risks and potential benefits before taking part.

\section{Results}

\section{Socio-demographic characteristics of participants}

Among the participants, $67.8 \%$ were female, $60.3 \%$ above 30 years of age , and $44.0 \%$ had attained secondary education and above. Regarding average monthly household income, over half of the participants $(53.7 \%)$ earned less than 40 US dollars, while $65.1 \%$ had at least one child under five years of age in their household, with $32.7 \%$ having two or more children (Table 1). 
Table 1: Socio-demographic characteristics of participants

\begin{tabular}{|c|c|c|}
\hline Characteristics & $\begin{array}{c}\text { Frequency } \\
(\mathrm{N}=727)\end{array}$ & $\begin{array}{c}\text { Percentage } \\
(\%)\end{array}$ \\
\hline \multicolumn{3}{|l|}{ Gender } \\
\hline Male & 234 & 32.2 \\
\hline Female & 493 & 67.8 \\
\hline \multicolumn{3}{|l|}{ Age (years) } \\
\hline $18-29$ & 289 & 39.8 \\
\hline$\geq 30$ & 438 & 60.3 \\
\hline \multicolumn{3}{|l|}{ Highest level of education } \\
\hline None & 78 & 10.7 \\
\hline Primary & 329 & 45.3 \\
\hline Secondary and above & 320 & 44.0 \\
\hline \multicolumn{3}{|l|}{ Occupation } \\
\hline Agriculture & 235 & 32.3 \\
\hline Business & 249 & 34.2 \\
\hline Housewife & 82 & 11.3 \\
\hline Unemployed & 108 & 14.9 \\
\hline Others & 53 & 7.3 \\
\hline \multicolumn{3}{|l|}{ Average household monthly income (US dollars) } \\
\hline$<40$ & 390 & 53.7 \\
\hline$\geq 40$ & 337 & 46.4 \\
\hline \multicolumn{3}{|l|}{ Religion } \\
\hline Catholic & 294 & 40.4 \\
\hline Anglican & 220 & 30.3 \\
\hline Pentecostal, Seventh Day Adventists, and other & 119 & 16.4 \\
\hline Muslim & 94 & 12.9 \\
\hline \multicolumn{3}{|l|}{ Status of participant in household } \\
\hline Not household head & 311 & 42.8 \\
\hline Household head & 416 & 57.2 \\
\hline \multicolumn{3}{|l|}{ Number of household members } \\
\hline $1-3$ & 228 & 31.4 \\
\hline $4-5$ & 231 & 31.8 \\
\hline$>5$ & 268 & 36.9 \\
\hline \multicolumn{3}{|c|}{ Household size regarding children under five years } \\
\hline Did not have at least one child & 254 & 34.9 \\
\hline Had at least one child & 473 & 65.1 \\
\hline \multicolumn{3}{|c|}{ Number of children under five years in the household } \\
\hline None & 254 & 34.9 \\
\hline 1 & 235 & 32.3 \\
\hline$\geq 2$ & 238 & 32.7 \\
\hline
\end{tabular}

\section{Malaria health seeking practices for children}

The majority of participants $(91.9 \%)$ said children suspected of having malaria should be taken for treatment on the same day the illness begins. Among the participants, $29.3 \%$ had children under five years of age in their household who were suspected of having malaria in the two weeks preceding the survey. Among these households with suspected sick children, treatment was sought mainly from government HCFs (33.7\%), private HCFs $(30.7 \%)$, and CHWs $(22.6 \%)$. The places where treatment for the children was first sought was mainly private HCFs $(28.1 \%)$, followed by government HCFs (25.6\%), CHWs $(3.0 \%)$, and others (13.0\%). The place where treatment was first sought for the children (government versus private HCF) was associated with participants' age $(p<0.001)$, education level $(p<0.001)$ and household income $(\mathrm{p}=0.011)$ (Table 2). Many of the participants $(59.8 \%)$ travelled 1 kilometre or less to seek treatment for the child. Others travelled between one to three kilometres $(22.1 \%)$ or more than 3 kilo- 
metres $(18.1 \%)$. A good number of the participants $(69.8 \%)$ sought treatment for the child on the same day the condition began. Over half of the participants
(53.7\%) did not pay for the treatment of the children. Those who paid for the treatment spent between $4-20$ US dollars (\$) $(36.2 \%)$, above $20 \$(6.8 \%)$ or less than $4 \$(3.4 \%)$.

Table 2: Place where treatment was sought for children under five years with suspected malaria

\begin{tabular}{|c|c|c|c|}
\hline Characteristic & Government facility & Private facility & p-value \\
\hline \multicolumn{3}{|l|}{ Gender } & \multirow[b]{3}{*}{0.928} \\
\hline Male & $25(53.2)$ & $22(46.8)$ & \\
\hline Female & $82(53.9)$ & $70(46.0)$ & \\
\hline \multicolumn{3}{|l|}{ Age (years) } & \multirow[b]{3}{*}{$<0.001 *$} \\
\hline $18-29$ & $32(37.2)$ & $54(62.8)$ & \\
\hline$\geq 30$ & $75(66.4)$ & $38(33.7)$ & \\
\hline \multicolumn{3}{|l|}{ Education level } & \multirow[b]{4}{*}{$<0.001 * *$} \\
\hline None & $12(75.0)$ & $4(25.0)$ & \\
\hline Primary & $62(65.3)$ & $33(34.7)$ & \\
\hline Secondary and above & $33(37.5)$ & $55(62.5)$ & \\
\hline \multicolumn{3}{|l|}{ Occupation } & \multirow[b]{6}{*}{0.135} \\
\hline Agriculture & $45(66.2)$ & $23(33.8)$ & \\
\hline Business & $29(46.8)$ & $33(53.2)$ & \\
\hline Housewife & $13(54.2)$ & $11(45.8)$ & \\
\hline Unemployed & $13(44.8)$ & $16(56.2)$ & \\
\hline Others & $7(43.7)$ & $9(56.2)$ & \\
\hline \multicolumn{3}{|l|}{ Household income } & \multirow[b]{3}{*}{$0.011 *$} \\
\hline$\leq \$ 40$ & $67(62.0)$ & $41(38.0)$ & \\
\hline$>\$ 40$ & $40(44.0)$ & $51(56.0)$ & \\
\hline \multicolumn{3}{|l|}{ Religion } & \multirow{5}{*}{0.055} \\
\hline Catholic & $37(54.4)$ & $31(45.6)$ & \\
\hline Anglican & $42(65.6)$ & $22(34.4)$ & \\
\hline $\begin{array}{l}\text { Pentecostal, Seventh Day } \\
\text { Adventist, and other }\end{array}$ & $17(43.6)$ & $22(56.4)$ & \\
\hline Muslim & $11(39.3)$ & $17(60.7)$ & \\
\hline \multicolumn{3}{|l|}{$\begin{array}{l}\text { Status of participant in } \\
\text { household }\end{array}$} & \multirow{3}{*}{0.444} \\
\hline Not household head & $50(51.0)$ & $48(49.0)$ & \\
\hline Household head & $57(56.4)$ & $44(43.6)$ & \\
\hline \multicolumn{3}{|l|}{$\begin{array}{l}\text { Number of household } \\
\text { members }\end{array}$} & \multirow{4}{*}{0.864} \\
\hline $1-3$ & $13(50.0)$ & $13(50.0)$ & \\
\hline $4-5$ & $38(52.8)$ & $34(47.2)$ & \\
\hline$>5$ & $56(55.4)$ & $45(44.5)$ & \\
\hline \multicolumn{3}{|c|}{$\begin{array}{l}\text { Hearing messages about malaria through mass } \\
\text { media (radio, television or newspapers) }\end{array}$} & \multirow[b]{3}{*}{0.076} \\
\hline Did not hear messages & $17(41.5)$ & $24(58.5)$ & \\
\hline Heard messages & $90(57.0)$ & $68(43.0)$ & \\
\hline \multicolumn{3}{|l|}{$\begin{array}{l}\text { Distance to the } \\
\text { nearest HCFs (kilometres) }\end{array}$} & \multirow{3}{*}{0.993} \\
\hline$\geq 5$ & $8(53.3)$ & $7(46.7)$ & \\
\hline$<5$ & $91(53.2)$ & $80(46.8)$ & \\
\hline \multicolumn{3}{|l|}{$\begin{array}{l}\text { Knowledge on the cause of } \\
\text { malaria }\end{array}$} & \multirow{3}{*}{0.289} \\
\hline Did not know the cause & $9(42.9)$ & $12(57.1)$ & \\
\hline Knew the cause & $98(55.1)$ & $80(44.9)$ & \\
\hline
\end{tabular}

Statistically significant at * $p<0.05 * *$ Fisher's Exact test 


\section{Household health seeking practices}

The nearest HCFs from participants' households were private clinics (39.3\%), government HCFs $(30.9 \%)$, and private hospitals $(20.1 \%)$. Other facilities mentioned by participants were pharmacies/drug shops (4.4\%). Many of the nearest HCFs $(62.3 \%)$ were less than one kilometre from the participants' homes. The other facilities were between one to three kilometres (17.2\%) or more than three kilometres $(10.9 \%)$. The most likely ways in which the participants would go to the nearest HCF from their households were walking (65.7\%), use commercial motorcycle $(28.2 \%)$, public transport $(3 \%)$, private car $(1.5 \%)$, or bicycle $(1.2 \%)$. The majority of participants $(71.7 \%)$ used the nearest HCF from their household the last time a household member was suspected to have malaria. Among participants whose households did not use the nearest facility, the reasons given were suspicion of no drugs being available $(33.3 \%)$, services being costly $(29.8 \%)$, poor services offered $(18.2 \%)$, services needed not offered $(8.6 \%)$, or poor health worker attitudes $(1.5 \%)$. A good number of participants $(68.4 \%)$ were aware of the existence of CHWs who distribute malaria medicines in their villages. However, among participants who were aware of the existence of CHWs, only $17.3 \%$ thought they had malaria medicines at the time. In $37.3 \%$ of households, school going children had missed school in the previous 6 months due to malaria, with a mean number of days missed of 15.3 (standard deviation \pm 29.9 ).
Knowledge and practices on Intermittent Preventive Treatment in pregnancy

Over half of the participants $(54.2 \%)$ were aware of sulfadoxine-pyrimethamine (SP) as the drug used for IPTp. Other drugs participants mentioned were chloroquine $(39.3 \%)$ and Coartem $(6.5 \%)$, while $39.3 \%$ did not know. Females were significantly more knowledgeable about IPT $p$ compared to males $(p<0.001)$. Among the females involved in the study ( $\mathrm{n}=493), 87 \% \mathrm{had}$ children. The majority of females with children (81.9\%) underwent IPTp when they were last pregnant. The main reasons given for those who did not undertake IPTp during their last pregnancy were: not being aware of the need (51.3\%); no HCF being available (24.4\%), and did not want $(16.7 \%)$. Among those who took drugs for IPTp, 73.6\% took SP, 4.8\% took chloroquine, while $16.2 \%$ did not know what they took. The majority of women $(94.6 \%)$ got IPTp the last time they were pregnant during ANC visits while for the rest, it was during another visit to a health facility. Among women who had a child in the five years preceding the study, 179 (63.0\%) had obtained two or more IPTp doses during their last pregnancy. Uptake of two or more IPTp doses was associated with higher education level $(p=0.006)$, having heard messages about malaria through mass media $(p=0.008)$, as well as knowing the recommended number of IPTp doses $(p<0.001)$ and drug used in IPTp $(\mathrm{p}<0.001)$ concerning the women (Table 3). 
Table 3: Association between uptake of IPTp with individual and household characteristics

\begin{tabular}{|c|c|c|c|}
\hline \multirow[t]{2}{*}{ Variables } & \multicolumn{2}{|c|}{ Uptake of 2 or more IPTp doses } & \multirow[t]{2}{*}{ p-value } \\
\hline & Yes & No & \\
\hline Overall $(\mathrm{n}=284)$ & $179(63.0)$ & $105(37.0)$ & \\
\hline \multicolumn{3}{|l|}{ Age (years) } & \multirow[b]{3}{*}{0.577} \\
\hline $18-29$ & $110(64.3)$ & $61(35.7)$ & \\
\hline$\geq 30$ & $69(61.1)$ & $44(38.9)$ & \\
\hline \multicolumn{3}{|l|}{ Education level } & \multirow[b]{4}{*}{$0.006 *$} \\
\hline None & $6(30.0)$ & $14(70.0)$ & \\
\hline Primary & $82(64.1)$ & $46(35.9)$ & \\
\hline Secondary and above & $91(66.9)$ & $45(33.1)$ & \\
\hline \multicolumn{3}{|l|}{ Occupation } & \multirow[b]{6}{*}{0.417} \\
\hline Agriculture & $44(55.7)$ & $35(44.3)$ & \\
\hline Business & $56(65.9)$ & $29(34.1)$ & \\
\hline Housewife & $41(70.7)$ & $17(29.3)$ & \\
\hline Unemployed & $32(62.7)$ & $19(37.2)$ & \\
\hline Others & $6(54.5)$ & $5(45.4)$ & \\
\hline \multicolumn{3}{|l|}{ Average monthly household income (US dollars) } & \multirow[b]{3}{*}{0.198} \\
\hline$\leq \$ 40$ & $83(59.3)$ & $57(40.7)$ & \\
\hline$>\$ 40$ & $96(66.7)$ & $48(33.3)$ & \\
\hline \multicolumn{3}{|l|}{ Religion } & \multirow[b]{5}{*}{0.112} \\
\hline Catholic & $79(68.7)$ & $36(31.3)$ & \\
\hline Anglican & $42(52.5)$ & $38(47.5)$ & \\
\hline Pentecostal, Seventh Day Adventist, and others & $36(67.9)$ & $17(32.1)$ & \\
\hline Muslim & $22(61.1)$ & $14(38.9)$ & \\
\hline \multicolumn{3}{|l|}{ Status of participant in household } & \multirow[b]{3}{*}{0.931} \\
\hline Not household head & $127(62.9)$ & $75(37.1)$ & \\
\hline Household head & $52(63.4)$ & $30(36.6)$ & \\
\hline \multicolumn{3}{|l|}{ Number of household members } & \multirow[b]{4}{*}{0.07} \\
\hline $1-3$ & $46(71.9)$ & $18(28.1)$ & \\
\hline $4-5$ & $71(65.7)$ & $37(34.3)$ & \\
\hline$>5$ & $62(55.4)$ & $50(44.6)$ & \\
\hline \multicolumn{3}{|c|}{ Household size regarding children under five years } & \multirow[b]{3}{*}{0.177} \\
\hline Did not have at least one child & $7(46.7)$ & $8(53.3)$ & \\
\hline Had at least one child & $172(63.9)$ & $97(36.1)$ & \\
\hline \multicolumn{3}{|c|}{$\begin{array}{l}\text { Hearing messages about malaria through mass media } \\
\text { (radio, television or newspaper) }\end{array}$} & \multirow[b]{3}{*}{$0.008 *$} \\
\hline Did not hear messages & $36(50.0)$ & $36(50.0)$ & \\
\hline Heard messages & $143(67.4)$ & $69(32.5)$ & \\
\hline \multicolumn{3}{|l|}{ Distance to the nearest HCF (kilometres) } & \multirow[b]{3}{*}{0.336} \\
\hline$\geq 5$ & $16(72.7)$ & $6(27.3)$ & \\
\hline$<5$ & $146(62.4)$ & $88(37.6)$ & \\
\hline Knowledge on the cause of malaria & & & \\
\hline Did not know the cause & $16(57.1)$ & $12(42.9)$ & \\
\hline Knew the cause & $163(63.7)$ & $93(36.3)$ & 0.497 \\
\hline Knowledge on recommended number of IPT & & & \\
\hline Did not know the recommended number & $59(45.0)$ & $72(54.9)$ & \\
\hline Knew the recommended number & $120(78.4)$ & $33(21.6)$ & $<0.001 *$ \\
\hline Knowledge on drug used for IPTp & & & \\
\hline Did not know the drug & $10(21.7)$ & $36(78.3)$ & \\
\hline Knew the drug & $169(71.0)$ & $69(28.9)$ & $<0.001 *$ \\
\hline
\end{tabular}

Statistically significant at $* p<0.05$ 


\section{Discussion}

This study explored health seeking practices among under five children on malaria related care as well as uptake of IPTp in Wakiso district, Uganda. Findings indicate that nearly $70 \%$ of caretakers of children suspected with malaria sought health care on the day of onset of symptoms, and most of them traveled 3 kilometres or less to the nearest HCF from their home. The choice of facility (government versus private) for seeking malaria related care for children was influenced by the participant's age, education level and household income. Uptake of IPTp among women who had a child within five years preceding the study was generally low $(63 \%)$ and influenced by level of education, having heard messages about malaria on mass media, as well as knowledge of the drug used during IPTp and recommended number of doses. The findings from our study emphasize the need for improving malaria health seeking practices including IPTp for better health outcomes among the population.

Early diagnosis and appropriate treatment of malaria is critical to minimize severe cases and associated mortality as well as interrupt transmission ${ }^{22}$. In our study, a high number of participants $(91.9 \%)$ indicated that children with suspected malaria ought to obtain medical care on the day of onset of symptoms. However, only $69.8 \%$ of those who had children with suspected malaria reported seeking care on the first day of onset of symptoms. The proportion of children suspected with malaria receiving care on the first day in our study is higher than that reported in a study in Equatorial Guinea $(47 \%)^{23}$ but lower than that reported in a Kenyan study $(86 \%)^{24}$. In our study, most caretakers first sought care for the children suspected of having malaria from formal health facilities (private $-28.1 \%$, government - $25.6 \%$ ) contrary to commonly observed trends in many African settings with high malaria transmission where people tend to manage malaria from home even where biomedical and health services are widely available ${ }^{23,25}$. A high number of caretakers seeking malaria health care for children from CHWs is expected in many low-and middle- income country (LMIC) settings where iCCM is being implemented as was established in our study $(22.6 \%)$. Involvement of CHWs in malaria management among children improves timely access to treatment hence a significant reduction in malaria infections and severe forms ${ }^{26}$. Although these CHWs are usually well known in the community, only $17.3 \%$ of participants in our study thought they had malaria medicines at the time. Indeed, lack of medicines among
CHWs especially for malaria treatment continues to be an impediment of community programmes aimed at combatting the disease ${ }^{27}$. The Ministry of Health $(\mathrm{MOH})$ should therefore ensure CHWs have the necessary logistics particularly medicines to enable them carry out malaria treatment amongchildren as a form of extending services to the community and reducing the burden of patients on HCFs.

A large proportion of participants would need to travel less than one kilometre $(62.3 \%)$ or between one to three kilometres $(17.2 \%)$ to the nearest HCF from their homes. A short distance to a HCF implies that physical access for health care is less of a challenge hence increasing the likelihood of utilizing health services. Evidence suggests that long distances to HCFs impedes utilisation of essential services as has been previously observed in Uganda $^{27,28}$. Our study established that more caretakers visited public HCFs (33.7\%) than private ones (30.7\%) for children suspected of having malaria. However, the first source of treatment for such children was private HCFs $(28.1 \%)$ compared to public facilities (25.6\%). These findings suggest that urgent care for children is sought from private HCFs which are many times more in number and nearer to households than public ones. Nevertheless, public HCFs were still visited especially if the private ones were unable to treat the sick children. However, access to healthcare in public HCFs is impeded by drug stockouts, high staff absenteeism, and long waiting hours ${ }^{28,29}$ which sometimes lead to seeking care from private providers. Our study established an association between income and the place where treatment was sought for children suspected of having malaria. This finding is in line with evidence which indicates that utilisation of private health care services increases with rise in education ${ }^{30,31,32}$. People with higher education are expected to be better informed about health care and usually have higher incomes hence they can afford private health services which sometimes could be of a higher quality than public $\mathrm{HCFs}^{33}$. Availability of various options of health services including both private and public facilities in communities is likely to increase access to care for malaria among children.

Regarding uptake of IPTp, $63.0 \%$ of women who had given birth in the five years preceding the study had obtained two or more IPTp doses during their last pregnancy. This level of utilisation of IPTp was lower than the national target of $80 \%$ for most African countries including Uganda ${ }^{1,34}$. The WHO has recommended three or more doses of IPTp for all pregnant women 
which many countries including Uganda are struggling to achieve1. Despite a low uptake of IPTp in our study, 94.6\% got it during ANC the last time they were pregnant. This finding is an indication that low IPTp could be related to low utilisation of ANC as has been found in other studies ${ }^{35,36}$. In addition, late timing of the first ANC visit has also been found to contribute to low uptake of IPTp ${ }^{37}$. Regular ANC attendance can improve uptake of optimal doses of IPTp hence sould be encouraged by various stakeholders including the $\mathrm{MOH}$ and partners.

Our study established that education was associated with uptake of IPTp among women who had a child five years preceding the study. Having attained higher education is likely to be associated with awareness of malaria prevention programmes. Indeed, individuals with higher education are more likely to be able to understand the benefits of IPTp for maternal and child survival as well as access ANC services ${ }^{34}$. Other studies have also highlighted the effect of education on increased uptake of IPT $\mathrm{p}^{38,39}$ hence an important factor in malaria prevention in pregnancy. Programmes aimed at increasing awareness on IPTp are therefore likely to particularly benefit women with low levels of education. Knowledge of the recommended number of doses as well as the drug used for IPTp were also associated with uptake of two or more doses. It is possible that this knowledge was because of uptake of IPTp in the first instance given health education is many times carried out during ANC. However, it is not possible to confirm causation given our study was cross-sectional. Nevertheless, other studies have indicated that limited understanding of IPTp among pregnant women affected uptake ${ }^{40,41}$. However, knowledge alone may not lead to improved practices regarding IPTp especially with various health system challenges in many LMICs including Uganda such as long distance to HCFs and regular stock out of medicines ${ }^{28}$.

This study had a number of strengths such as involving both women and men in IPTp issues; explored health seeking practices for children, women and the general household; and also involved several parishes that had rural and peri-urban populations. Involving men in IPTp is particularly of key public health importance as male involvement has been shown to contribute to better maternal health outcomes including in developing countries ${ }^{42}$. Nevertheless, the study had some limitations such as malaria among children being suspected (as opposed to being actual). In addition, there was potential for recall bias since the study involved asking women questions concerning their pregnancy in the previous five years. However, the specific information that was asked related to only their last pregnancy which for many was within the previous few years hence reducing recall bias. In addition, information concerning the last pregnancy is likely to be known most by women in comparison with earlier pregnancies. Lastly, only univariate and bivariate analysis for associations were done hence confounding could not have been controlled for. These limitations notwithstanding, the findings of this study can inform interventions to improve malaria health seeking practices as well as guide future research in Uganda and beyond.

\section{Conclusion}

This study provides useful insights into malaria health seeking practices including delays in taking children suspected of having the disease to health facilities, and low coverage of IPTp. There is need to improve health malaria seeking practices among childrn and pregnant women to reduce morbidity and mortality related to the disease. Programmes should therefore be designed to increase awareness on the importance of early seeking for health care for children and IPTp, as well as address other health system challenges affecting health seeking behaviour among the community.

\section{Competing interests}

The authors declare that they have no competing interests.

\section{Acknowledgements}

The work was supported by Training Health Researchers into Vocational Excellence (THRiVE) in East Africa, grant number 087540 , funded by Wellcome Trust. The funder did not have any role in design of the study and collection, analysis, and interpretation of data, and in writing the manuscript. We thank the research assistants who participated in data collection and entry. Our appreciation also goes to the village leaders and community mobilizers especially Henry Kajubi and Henry Bugembe for the support offered. We also thank the research participants for accepting to take part in the study.

\section{Authors' contributions}

DM and MBM conceptualised the study and were involved in its design, data analysis, interpretation of results and manuscript writing. RN, STW, SK and JNM were involved in data analysis, interpretation of results 
and manuscript writing. All authors read and approved the final manuscript.

\section{References}

1. WHO. World malaria report 2019. Geneva: WHO; 2019.

2. Dellicour S, Tatem A, Guerra C, Snow R, ter Kuile F. Quantifying the number of pregnancies at risk of malaria in 2007: a demographic study. PLoS Med 2010; 7(1): e1000221.

3. Lagerberg RE. Malaria in pregnancy: A literature review. J Midwifery Womens Health 2008; 53(3):209-15.

4. Rogerson SJ, Mwapasa V, SR. M. Malaria in pregnancy: linking immunity and pathogenesis to prevention. Am J Trop Med Hyg 2007; 77(6):14-22.

5. WHO. Intermittent Preventive Treatment of Malaria in Pregnancy Using Sulfadoxine-Pyrimethamine (IPTp-SP): Updated WHO Policy Recommendation. Geneva: WHO; 2012.

6. WHO. WHO policy brief for the implementation of intermittent preventive treatment of malaria in pregnancy using sulfadoxine-pyrimethamine (IPTp-SP) 2014. Geneva: WHO; 2014.

7. Olukoya OO, Adebiyi OA. Missed opportunities for intermittent preventive treatment for malaria in pregnancy in nigeria: evidence from demographic and health survey in Nigeria 2013. Ann. Ib. Postgrad. Med 2017; 15(2):88-95.

8. Van Eijk AM, Hill J, Alegana VA, Kirui V, Gething PW, ter Kuile FO. Coverage of malaria protection in pregnant women in sub-Saharan Africa: a synthesis and analysis of national survey data. Lancet Infect Dis 2011; 11(3):190-207.

9. Florey L. Preventing malaria during pregnancy in sub-Saharan Africa: determinants of effective IPTp delivery. DHS Analytical Studies No. 39. 2013; 1-59.

10. Arnaldo P, Rovira Vallbona E, Lang SJ, Crizolgo S, Pieter G, Driss Chiheb, et al. Uptake of intermittent preventive treatment and pregnancy outcomes: health facilities and community surveys in Chókwè district, southern Mozambique. Malar J 2018; 17(1):109.

11. van Eijk AM, Ayisi JG, ter Kuile FO, Slutsker L, Otieno JA, Adondi JO. Implementation of intermittent preventive treatment with sulphadoxine-pyremethamine for control of malaria in pregnancy in Kisumu western Kenya. Trop. Med. Int. Health 2004; 9(5):630-7. 12. Hill J, Kazembe P. Reaching the Abuja target for intermittent preventive treatment of malaria in pregnancy in African women: a review of progress and operational challenges. Trop Med Int Health 2006; 11(4):409-18.

13. Mbonye AK, Neema S, Magnussen P. Treatment seeking practices for malaria in pregnancy among rural women in Mukono District, Uganda. J. Biosoc. Sci. 2006; 38(2):221-37.

14. WHO. Monitoring the building blocks of health systems: a handbook of indicators and their measurement strategies. Geneva: WHO; 2010.

15. Kiwanuka NG: Malaria morbidity and mortality in Uganda. J Vect Borne Dis 2003; 40:16-19.

16. Uganda Bureau of Statistics (UBOS) and ICF International. Uganda Malaria Indicator Survey 2014-15. 2015. Kampala: UBOS; 2015.

17. Uganda Bureau of Statistics (UBOS). Uganda Demographic and Health Survey (UDHS) 2016. Kampala: UBOS; 2016.

18. Yeka A, Gasasira A, Mpimbaza A, Achan J, Nankabirwa J, Nsobya S, et al. Malaria in Uganda: challenges to control on the long road to elimination. I. Epidemiology and current control efforts. Acta Tropica 2012; 121(3):184-95.

19. WHO. Intermittent Preventive Treatment in Pregnancy. Geneva: WHO; 2019.

20. Uganda Bureau of Statistics (UBOS). National population and housing census 2014. Provisional results. 2014. Kampala: UBOS; 2014.

21. Musoke D, Miiro G, Karani G, Morris K, Kasasa S, Ndejjo R, et al. Promising perceptions, divergent practices and barriers to integrated malaria prevention in Wakiso district, Uganda: a mixed methods study. PLoS One 2015; 10(4):e0122699.

22. Sharma VR: When to seek health care: A duration analysis for malaria patients in Nepal. Soc. Sci. Med 2008; 66(12):2486-94.

23. Romay-Barja M, Cano J, Ncogo P, Nseng G, Santana-Morales MA, Valladares B, et al. Determinants of delay in malaria care-seeking behaviour for children 15 years and under in Bata district, Equatorial Guinea. Malar J 2016; 15:187.

24. Chuma J, Okungu V, Molyneux C. Barriers to prompt and effective malaria treatment among the poorest population in Kenya. Malar J 2010; 9:144.

25. Williams HA, Jones CO: A critical review of behavioral issues related to malaria control

in sub-Saharan Africa: what contributions have social scientists made? Soc Sci Med 2004, 59(3):501-523.

26. Goodman C, Brieger W, Unwin A, Mills A, Meek $\mathrm{S}$, Greer G. Medicine sellers and malaria treatment in sub-Saharan Africa: what do they do and how can their practice be improved? Am J Trop Med Hyg 2007;77(6 Suppl):203-18.

27. Musoke D, Ndejjo R, Atusingwize E, Mukama T, Ssemugabo C, Gibson L. Performance of community 
health workers and associated factors in a rural community in Wakiso district, Uganda. Afr Health Sci. 2019; 19(3):2784-97

28. Musoke D, Boynton P, Butler C, Musoke M. Health seeking behaviour and challenges in utilising health facilities in Wakiso district, Uganda. Afr Health Sci.2015; 14(14):1046-55.

29. Kiguli J, Ekirapa-Kiracho E, Okui O, Mutebi A, MacGregor H, Pariyo GW. Increasing access to quality health care for the poor: Community perceptions on quality care in Uganda. Patient Prefer Adher 2009; 3:7785.

30. Awoke MA, Negin J, Moller J, Farell P, Yawson AE, Biritwum RB, et al. Predictors of public and private healthcare utilization and associated health system responsiveness among older adults in Ghana. Glob. Health Action 2017; 10(1):1301723.

31. Saeed BII, Yawson AE, Nguah S, Agyei-Baffour P, Emmanuel N, Ayesu E. Effect of socio-economic factors in utilization of different healthcare services among older adult men and women in Ghana. BMC Health Serv Res 2016; 16(a):390.

32. Hammond WP, Matthews D, Corbie-Smith G. Psychosocial factors associated with routine health examination scheduling and receipt among African American men. J Natl Med Assoc 2010; 102(4):276-289.

33. Fletcher JM, Frisvold DE. Higher Education and Health Investments: Does More Schooling Affect Preventive Health Care Use? J Hum Cap 2009; 3(2):144-176. 34. Okethwangu D, Opigo J, Atugonza S, Kizza CT, Nabatanzi M, Biribawa C, et al. Factors associated with uptake of optimal doses of intermittent preventive treatment for malaria among pregnant women in Uganda: analysis of data from the Uganda Demographic and Health Survey, 2016. Malar J 2019; 18(1):250.

35. Ndyomugyenyi R, Katamanywa J. Intermittent preventive treatment of malaria in pregnancy (IPTp): do frequent antenatal care visits ensure access and compliance to IPTp in Ugandan rural communities? Trans $R$ Soc Trop Med Hyg. 2010;104(8):536-40

36. Arnaldo P, Cambe MI, Magaço A, Chicumbe S, Rovira-Vallbona E, Rosanas-Urgell A, et al. Access to and use of preventive intermittent treatment for Malaria during pregnancy: A qualitative study in the Chókwè district, Southern Mozambique. PLoS One. 2019;14(1):e0203740.

37. Anchang-Kimbi JK, Achidi EA, Apinjoh TO, Mugri $\mathrm{RN}$, Chi HF, Tata RB, et al. Antenatal care visit attendance, intermittent preventive treatment during pregnancy (IPTp) and malaria parasitaemia at delivery. Malar J. 2014; 13:162

38. Sambili B, Kimambo R, Peng Y, Ishunga E, Matasha E, Matumu G, et al. Factors influencing anti-malarial prophylaxis and iron supplementation non-compliance among pregnant women in Simiyu Region, Tanzania. Int J Environ Res Public Health 2016; 13(7):626.

39. Kibusi SM, Kimunai E, Hines CS. Predictors for uptake of intermittent preventive treatment of malaria in pregnancy (IPTp) in Tanzania. BMC Public Health 2015; 15:540.

40. Launiala A, Honkasalo M-L. Ethnographic study of factors influencing compliance to intermittent preventive treatment of malaria during pregnancy among Yao women in rural Malawi. Trans R Soc Trop Med Hyg 2007; 101(10):980-9.

41. Diala CC, Pennas T, Marin C, Belay KA. Perceptions of intermittent preventive treatment of malaria in pregnancy (IPTp) and barriers to adherence in $\mathrm{Na}$ sarawa and Cross River States in Nigeria. Malar J. 2013; 12:342.

42. Yargawa J, Leonardi-Bee J. Male involvement and maternal health outcomes: systematic review and meta-analysis. J Epidemiol Community Health. 2015;69(6):604612. 